\title{
CASO POLINATO: A INOVAÇÃO COMO DIFERENCIAL, A RENTABILIDADE COMO DESAFIO
}

THE CASE OF POLINATO: INNOVATION AS COMPETITIVE ADVANTAGE, PROFITABILITY AS A CHALLENGE

CASO POLINATO: LA INNOVACIÓN COMO DIFERENCIAL, LA RENTABILIDAD COMO DESAFIO

\author{
FLAVIO FACHINELLI \\ Especialista \\ Intelligenza Conhecimento e Inovação - Brasil \\ flavio@intelligenza.com.br
}

ANA CRISTINA FACHINELLI

Doutora

Universidade de Caxias do Sul afachinelli@gmail.com

\author{
FERNANDA PAULETTO D'ARRIGO \\ Mestre \\ Universidade de Caxias do Sul \\ fernanda.darrigo@gmail.com
}

Submetido em: 24/03/2016

Aprovado em: 11/04/2018

Doi: alcance.v25n1(Jan/Abr).p95-105

\begin{abstract}
RESUMO
O caso apresenta a trajetória da Polinato, empresa líder no segmento de formulação de poliuretanos e sua capacidade de desenvolvimento de produtos inovadores e customizados. A inovação é a estratégia que mantém a empresa na liderança. Todavia a rentabilidade decorrente das inovações está aquém da esperada. Para manter e refinar a capacidade inovadora com rentabilidade, a empresa solicitou um financiamento para custear parcialmente um audacioso Projeto de Pesquisa de Desenvolvimento. O dilema dos sócios está na tomada de decisão sobre assinar o contrato e comprometer-se com o financiamento para acelerar os processos de inovação, ou recusar o financiamento e inovar num ritmo mais lento com financiamentos de taxas maiores. 0 objetivo desse caso para ensino é promover a reflexão e a discussão sobre estratégia, competitividade e inovação, elaborado para utilização em disciplinas relacionadas a este tema.
\end{abstract}

Palavras-chaves: Inovação, crescimento, rentabilidade.

\section{ABSTRACT}

This case presents the trajectory of Polinato - industry leader in the polyurethane formulation segment - and its ability to develop innovative and customized products. Innovation is a strategy that keeps the company in the lead. However, the profitability resulting from its innovations is below expectations. To maintain and refine the innovative capacity while ensuring profitability, the company recently requested financing to partially cover a bold Development Research Project. The dilemma facing the company's partners is the decision on whether to sign the contract and commit to the financing, which will accelerate the company's innovation processes, or not to take the financing and innovate at a slower pace instead, avoiding the heavy financing fees. It is hoped that this teaching case will promote 
reflection and discussion on strategy, competitiveness and innovation. It is designed for use in disciplines related to the themes of innovation, strategy and entrepreneurship.

Keywords: innovation, growth, profitability.

\section{RESUMEN}

El caso presenta la trayectoria de Polinato, una empresa líder en el segmento de formulación de poliuretanos y su capacidad de desarrollo de productos innovadores y personalizados. La innovación es la estrategia que mantiene la empresa en el liderazgo. Sin embargo, la rentabilidad resultante de las innovaciones está por debajo de la esperada. Para mantener y refinar la capacidad innovadora con rentabilidad, la empresa solicito una financiación para costear parcialmente un audaz Proyecto de Investigación de Desarrollo. El dilema de los socios está en la toma de decisión sobre firmar el contrato y comprometerse con la financiación para acelerar los procesos de innovación, o recusar la financiación e innovar en un ritmo más lento con financiamientos de tasas mayores. El objetivo de este caso para la enseñanza es promover la reflexión y la discusión sobre estrategia, competitividad e innovación, elaborado para la utilización en disciplinas relacionadas a este tema.

Palabras clave: Innovación, crecimiento, rentabilidad.

\section{INTRODUÇÃO}

O dia amanheceu ensolarado na maior cidade brasileira. É a segunda sexta-feira do primeiro mês de 2011. A Marginal Tietê já está lotada de veículos e o trânsito para. Piero olha para o telefone celular que está no banco do carro à sua direita, pois pretende avisar o pessoal da empresa que irá se atrasar para chegar a Sorocaba. Para sua surpresa, o visor indica que não há sinal. Seu jeito entusiasmado o faz pensar: "Que bom! Assim posso ficar uns minutos fora do mundo e preparar melhor meu dia". Nesse momento, sintoniza o rádio na estação local para saber $\mathrm{o}$ que pode ter ocasionado 0 inesperado congestionamento. $O$ locutor avisa que houve um grande acidente logo adiante e que os veículos já estão sendo removidos, não há mortos. "Graças a Deus", pensa Piero.

No meio deste caos urbano, lembranças de um passado recente da sua empresa surgem vividamente em sua mente. Seu pensamento vai do início modesto da empresa química, num pequeno galpão, aos contatos frequentes com grandes grupos empresariais que o buscam na expectativa de resolver seus gargalos de produção. Com a fundação da Polinato tudo mudou para Piero: o estilo de vida, agora muito mais confortável; a diminuição do tempo para a família; a grande responsabilidade que ele sente nos ombros por conta de tantos funcionários que dependem do desempenho da empresa; a preocupação constante com o pagamento dos inúmeros empréstimos bancários que permitem à empresa continuar operando.

E um leve sorriso maroto surge em seu rosto quando se lembra da recente notícia da aprovação do projeto de inovação pela Finep ${ }^{1}$, o que poderá representar um novo horizonte para a empresa. Mas ao mesmo tempo uma preocupação, já que é o maior financiamento da história da empresa. Inúmeras perguntas surgiram à cabeça de Piero naquele momento. Deveria assinar o contrato de financiamento com Finep e investir um plano de inovação para a empresa? Isso aumentaria a rentabilidade da empresa? Nesse momento o trânsito volta a andar lentamente, o sinal retorna e o celular toca. É o pessoal da empresa: o dia finalmente começou!

\section{TRAJETÓRIA DA POLINATO}

A Polinato foi fundada no ano de 1997 por dois executivos da indústria química e um empresário do ramo da publicidade, que também possuía conhecimento no ramo de poliuretano. A Polinato iniciou suas atividades em Jundiaí (SP), instalada em um pequeno galpão. Com o crescimento da empresa, em dezembro de 2002, os sócios optaram por transferir a indústria para um prédio mais amplo, com melhores condições fabris em Sorocaba (SP). Em 2003, a Polinato assumiu a liderança de mercado entre as empresas de sistema de poliuretano independentes. Uma jovem empresa com talento de "gente grande". Neste mesmo ano a Polinato recebeu a certificação ISO 90012000, o que aumentaria a gama de clientes que demandavam que os fornecedores possuíssem esta certificação.

\footnotetext{
1 Financiadora de Estudos e Projetos - Agência de Inovação subordinada ao Ministério de Ciência, Tecnologia e Inovação.
} 
0 ano de 2004 foi marcado pelo desenvolvimento inovador de um pré-polímero à base de TDI ${ }^{2}$. Devido à falta de $\mathrm{MDI}^{2}$ no mercado brasileiro, este produto fez um enorme sucesso no mercado para aplicação em isolamento térmico.

Em 2005, a Polinato assinou um contrato de exclusividade com a americana Foam Supplies para comercialização de AEPU (Agente Expansor para Puliuretanos ${ }^{3}$ ) em toda a América Latina, agente expansor ecologicamente correto para espumas rígidas. Neste mesmo ano, em parceria com a Foam Supplies, a Polinato registrou 4 novas patentes de poliuretano utilizando tecnologia ambientalmente correta.

$O$ ano de 2006 marcou o início das exportações da Polinato para Argentina, Chile, Colômbia e Itália. Neste mesmo ano a empresa assinou o termo do programa Atuação Responsável da ABIQUIM (Associação Brasileira da Indústria Química). Em termos de inovação, o ano de 2006 ficou marcado por uma grande inovação: 0 desenvolvimento da espuma viscoelástica "All MDI" para caixote e injeção em moldes. Rapidamente esta espuma se tornou um sucesso de vendas. E o outro fato importante deste ano foi a aquisição da divisão de sistemas de poliuretano da Char Química, terceira maior concorrente da Polinato.

Os dois anos seguintes foram marcados por muitas inovações, lançamentos de novos produtos, participação em importantes feiras e grande crescimento das vendas. Em 2009 a empresa desenvolveu a espuma viscoelástica ALL MDI branca para colchões em máquina contínua. No mesmo ano, inicia-se a exportação de sistemas de alto desempenho para empresas de colchão para toda a América Latina.

A partir deste momento, a Polinato passa a ser reconhecida pelo mercado como uma fornecedora de soluções tecnológicas, mais do que produtos químicos. Torna-se, portanto, referência entre as empresas de sistemas de poliuretano. Todo este vertiginoso crescimento teve seu custo financeiro e econômico. Mesmo tendo um faturamento próximo à casa dos $\mathrm{R} \$ 100$ milhões em pouco mais de 14 anos, a estrutura financeira atual da empresa se mostra frágil, com grande dependência do capital de terceiros, em especial, dos bancos. Sua capacidade de inovar e encontrar soluções customizadas contribuiu para a fidelização de muitos clientes, o que garante um bom nível de receitas financeiras mensais, mas o resultado líquido ainda está aquém do que os sócios desejam.

Em 2010, a Polinato participou do Prêmio Esforço e pela Revista Trust de Empreendedorismo ${ }^{4}$, e foi selecionada entre as 12 empresas finalistas. Neste processo, a Polinato foi analisada criteriosamente por profissionais especializados. Além do processo de análise, a empresa teve a oportunidade de participar de reuniões com profissionais de referência em inovação, os quais elogiaram o crescimento vertiginoso da empresa e forneceram importantes orientações para perenizar o crescimento consistente dos últimos anos. 0 relato da revista Trust de Empreendedorismo definiu o perfil da Polinato da seguinte forma:

\begin{abstract}
"Muitos produtos usados em nosso dia-a-dia têm algo em comum - o poliuretano, material que pode rechear colchões e volantes de automóveis. Fundada em 1997 a Polinato produz fórmulas que dão origem ao material. Para conseguir espaço num mercado dominado por multinacionais, os sócios investiram num nicho deixado de lado por elas -, pequenas e médias empresas. A Polinato possui um laboratório do qual saem boas surpresas. A última foi um material não poluente para ser usado como isolante térmico em geladeiras. 0 produto chamou a atenção da Coca-Cola, que aconselhou a utilização da nova tecnologia pelo varejo que trabalha com a marca e passou a indicar a Polinato para seus parceiros mundo a fora. Com isso, a empresa conquistou clientes na Índia, na Argentina e no México: 'A Polinato trouxe inovação para um mercado que era dominado por multinacionais'. (Jurado da premiação)
\end{abstract}

A Polinato teve como prioridade o constante desenvolvimento tecnológico. A empresa entendeu desde cedo que o seu valor maior seria diretamente proporcional à quantidade de conhecimento que pudesse absorver, tratar e disseminar para promover a mudança. Sendo ela uma fornecedora de matérias-primas que serão utilizadas no processo final, sabe que depende dela acelerar o processo de inclusão de seus clientes rumo aos novos tempos. Em termos de PU, novos tempos pressupõem equalizar duas variáveis fundamentais: equilíbrio ecológico

\footnotetext{
2 TDI e MDI são Isocianatos usados com base na produção de diversos PUs. Basicamente são a matéria-prima para a produção de polímeros.

${ }^{3}$ Nome fictício apenas para fins de relato.

${ }^{4}$ Nome fictício.
}

Revista Alcance - Eletrônica - vol. 25 - n. 1 - Jan./Abr. 2018 
e viabilidade econômica. Estas são duas das maiores demandas das indústrias manufatureiras. As questões ambientais estão ligadas a um grande arcabouço legal e de escassez de fontes de recursos naturais. As questões econômicas referem-se a um cenário de crescente, e implacável, competição global. O sucesso no negócio da Polinato depende da competência nestes dois eixos.

A Polinato nasceu e cresceu pela percepção dos seus dirigentes de que este novo cenário apresentava grandes oportunidades. A regra principal do funcionamento do cenário industrial atual é a mudança. Sendo assim, este projeto é um importante passo neste esforço da Polinato por continuar sendo uma empresa de vanguarda tecnológica, reconhecida pela sua grande capacidade de customização e agilidade de desenvolvimento. No cenário em que a empresa atua, conceitos como "agilidade estratégica" e "economia de recursos" devem ser bem conhecidos e praticados. Mas o Programa de P\&D+I prevê bem mais do que a agilidade.

\subsection{Produtos/Serviços, Clientes e Fornecedores}

Os principais produtos da empresa Polinato são apresentados na Tabela 1, classificados por percentuais de fabricação:

Tabela 1 - Relação dos produtos da empresa em ordem de importância

\begin{tabular}{l|c}
\multicolumn{1}{c|}{ Produtos } & Percentuais \\
\hline Isocianatos & $45 \%$ \\
\hline Isolamentos & $24 \%$ \\
\hline Flexíveis & $13 \%$ \\
\hline Semirrígidos & $6 \%$ \\
\hline Rígidos Estruturais & $2 \%$ \\
\hline Elastômeros & $3 \%$ \\
\hline Outros & $7 \%$ \\
\hline
\end{tabular}

Fonte: Gerência Industrial da Polinato.

Os produtos destinam-se aos mercados e às aplicações da indústria automotiva, moveleira, bem como a indústria de aglomerante, espumas industriais, isolamento térmico, indústrias da refrigeração, adesivos, construção civil, colchões e móveis para escritório. Assim, os principais clientes da empresa são empresas nacionais e multinacionais dos segmentos da indústria plástica, moveleira, alimentícia e automotiva. Já os principais fornecedores são empresas farmacêuticas, químicas e de refrigeração.

\subsection{Dados e índices econômico-financeiros}

A fim de apresentar a Polinato por seus números, a Tabela 2 apresenta uma síntese de indicadores dos balanços patrimoniais dos 3 anos anteriores ao cenário do dilema. Já a Tabela 3 apresenta os indicadores de liquidez, retornos sobre os ativos e o patrimônio líquido e o grau de imobilização dos ativos.

\begin{tabular}{l|r|r|r|r}
\hline \multicolumn{1}{c|}{ Contas } & \multicolumn{1}{c|}{$\mathbf{2 0 0 7}$} & \multicolumn{1}{c|}{$\mathbf{2 0 0 8}$} & \multicolumn{1}{c|}{$\mathbf{2 0 0 9}$} & \multicolumn{1}{c}{$\mathbf{2 0 1 0}^{*}$} \\
\hline Ativo Circulante & \multicolumn{1}{c|}{$13.833 .953,97$} & $17.013 .641,68$ & $16.673 .652,41$ & $17.000 .000,00$ \\
\hline Permanente & $2.854 .289,18$ & $3.643 .550,10$ & $3.201 .174,06$ & $3.800 .000,00$ \\
\hline Total do Ativo & $16.688 .243,15$ & $20.657 .191,78$ & $19.874 .826,42$ & $20.800 .000,00$ \\
\hline Passivo Circulante & $15.830 .287,85$ & $18.012 .395,37$ & $17.291 .373,52$ & $16.500 .000,00$ \\
\hline Passivo de Longo Prazo & - & $884.055,45$ & $76.204,31$ & $600.000,00$ \\
\hline Capital Social & $604.000,00$ & $606.000,00$ & $606.000,00$ & $606.000,00$ \\
\hline Patrimônio Líquido & $857.955,30$ & $1.760 .740,96$ & $2.507 .248,64$ & $3.094 .000,00$ \\
\hline Receita bruta & 41.340 .000 & 47.541 .000 & 54.672 .150 & 62.000 .000 \\
\hline Deduções da receita & $(10.454 .225)$ & $(12.022 .358)$ & $(13.825 .712)$ & $(16.000 .000)$ \\
\hline Receita operacional líquida & 30.885 .775 & 35.518 .642 & 40.846 .438 & 46.000 .000 \\
\hline Custo dos produtos vendidos & $(20.252 .320)$ & $(23.050 .168)$ & $(26.267 .693)$ & $(30.000 .000)$ \\
\hline
\end{tabular}


(Conclusão)

\begin{tabular}{l|r|r|r|r}
\hline \multicolumn{1}{c|}{ Contas } & \multicolumn{1}{c|}{$\mathbf{2 0 0 7}$} & \multicolumn{1}{c|}{$\mathbf{2 0 0 8}$} & \multicolumn{1}{c|}{$\mathbf{2 0 0 9}$} & \multicolumn{1}{c}{$\mathbf{2 0 1 0}^{*}$} \\
\hline Lucro bruto & 10.633 .455 & 12.468 .474 & 14.578 .745 & 16.000 .000 \\
\hline Despesas operacionais & $(8.327 .302)$ & $(9.324 .815)$ & $(10.381 .821)$ & $(12.000 .000)$ \\
\hline Lucro líquido antes do IR/CS & 2.306 .154 & 3.143 .659 & 4.196 .924 & 4.000 .000 \\
\hline $\begin{array}{l}\text { Imposto de Renda/Contribuição } \\
\text { Social }\end{array}$ & $(760.092)$ & $(1.044 .844)$ & $(1.402 .954)$ & $(1.500 .000)$ \\
\hline Lucro líquido do exercício & 1.546 .061 & 2.098 .815 & 2.793 .970 & 2.500 .000 \\
\hline
\end{tabular}

Tabela 2 - Resumo do balanço patrimonial e principais indicadores

Fonte: Departamento Financeiro da Empresa.

*Estimativas da empresa.

Tabela 3 - Indicadores da Polinato

\begin{tabular}{l|c|c|c|c}
\hline \multicolumn{1}{c|}{ Índices } & $\mathbf{2 0 0 7}$ & $\mathbf{2 0 0 8}$ & $\mathbf{2 0 0 9}$ & $\mathbf{2 0 1 0}$ \\
\hline Liquidez Corrente & $\mathbf{0 , 8 7}$ & $\mathbf{0 , 9 4}$ & $\mathbf{0 , 9 6}$ & $\mathbf{1 , 0 3}$ \\
\hline Retorno sobre os ativos (ROA) & 0,09 & 0,10 & 0,14 & 0,12 \\
\hline Retorno sobre o PL (ROE) & 1,80 & 1,19 & 1,11 & 0,81 \\
\hline Grau de Imobilização do Ativo & 0,17 & 0,18 & 0,16 & 0,18 \\
\hline
\end{tabular}

Fonte: Cálculos dos autores com base nos balanços e DREs.

\subsection{Perfil dos fundadores e dos funcionários da Polinato}

O Quadro 1 apresenta o perfil dos fundadores da empresa com a formação e a experiência no setor de atividades da empresa.

Quadro 1 - Perfil dos fundadores e dos funcionários da Polinato

\begin{tabular}{|c|c|c|c|}
\hline Nome do sócio & $\begin{array}{c}\text { Função/função } \\
\text { exercida na } \\
\text { Polinato }\end{array}$ & Formação & Experiência no setor \\
\hline Clodoaldo & $\begin{array}{l}\text { Diretor de Pesquisa } \\
\text { e Desenvolvimento } \\
\text { e Diretor Industrial }\end{array}$ & $\begin{array}{l}\text { Engenharia } \\
\text { Química }\end{array}$ & $\begin{array}{l}\text { Técnico de pesquisa e desenvolvimento no Centro de } \\
\text { Pesquisas e Desenvolvimento de uma empresa química } \\
\text { por } 6 \text { anos. } \\
\text { Engenheiro de pesquisa e desenvolvimento de } \\
\text { poliuretano por } 4 \text { anos, tornando-se diretor de pesquisa e } \\
\text { desenvolvimento de sistemas de poliuretano. Saiu da } \\
\text { empresa para fundar a Polinato. }\end{array}$ \\
\hline Piero & Diretor Comercial & $\begin{array}{l}\text { Administração } \\
\text { de Empresas }\end{array}$ & $\begin{array}{l}\text { Gerente comercial de uma empresa de sistemas e } \\
\text { fabricação de polímeros por } 12 \text { anos. Em 1996, assumiu } \\
\text { a gerência comercial de uma indústria química, onde } \\
\text { conheceu Clodoaldo. Saiu da empresa para fundar a } \\
\text { Polinato. }\end{array}$ \\
\hline Noé & $\begin{array}{l}\text { Coordenador da } \\
\text { área administrativa, } \\
\text { marketing e } \\
\text { financeira. }\end{array}$ & $\begin{array}{l}\text { Jornalista e } \\
\text { publicitário }\end{array}$ & $\begin{array}{l}\text { Coordenou a área de comunicação de uma empresa } \\
\text { petroquímica e foi diretor do programa Pró-Espuma } \\
\text { Qualidade (1989 até 1992). Em } 1993 \text { abriu a agência de } \\
\text { publicidade, quando em1997, participou da fundação da } \\
\text { Polinato Química Ltda. }\end{array}$ \\
\hline
\end{tabular}

Fonte: Elaborado pelos autores.

Além dos empreendedores, a empresa conta com 54 funcionários, sendo que 13 profissionais possuem ensino superior completo e 22 técnicos, os quais ocupam postos-chaves na empresa. Os profissionais que ocupam os postos-chaves são capacitados e com experiência na função. A empresa conta ainda com 19 profissionais com ensino médio completo para desempenhar atividades operacionais mais simples e rotineiras.

Revista Alcance - Eletrônica - vol. 25 - n. 1 - Jan./Abr. 2018 
Uma das principais características da Polinato é o foco na inovação tecnológica como prioridade da gestão. Mesmo sendo uma empresa jovem, foram inúmeros desenvolvimentos. Alguns projetos de inovação conduzidos pela empresa são apresentados no Quadro 2.

Quadro 2 - Principais projetos de Inovação conduzidos pela Polinato

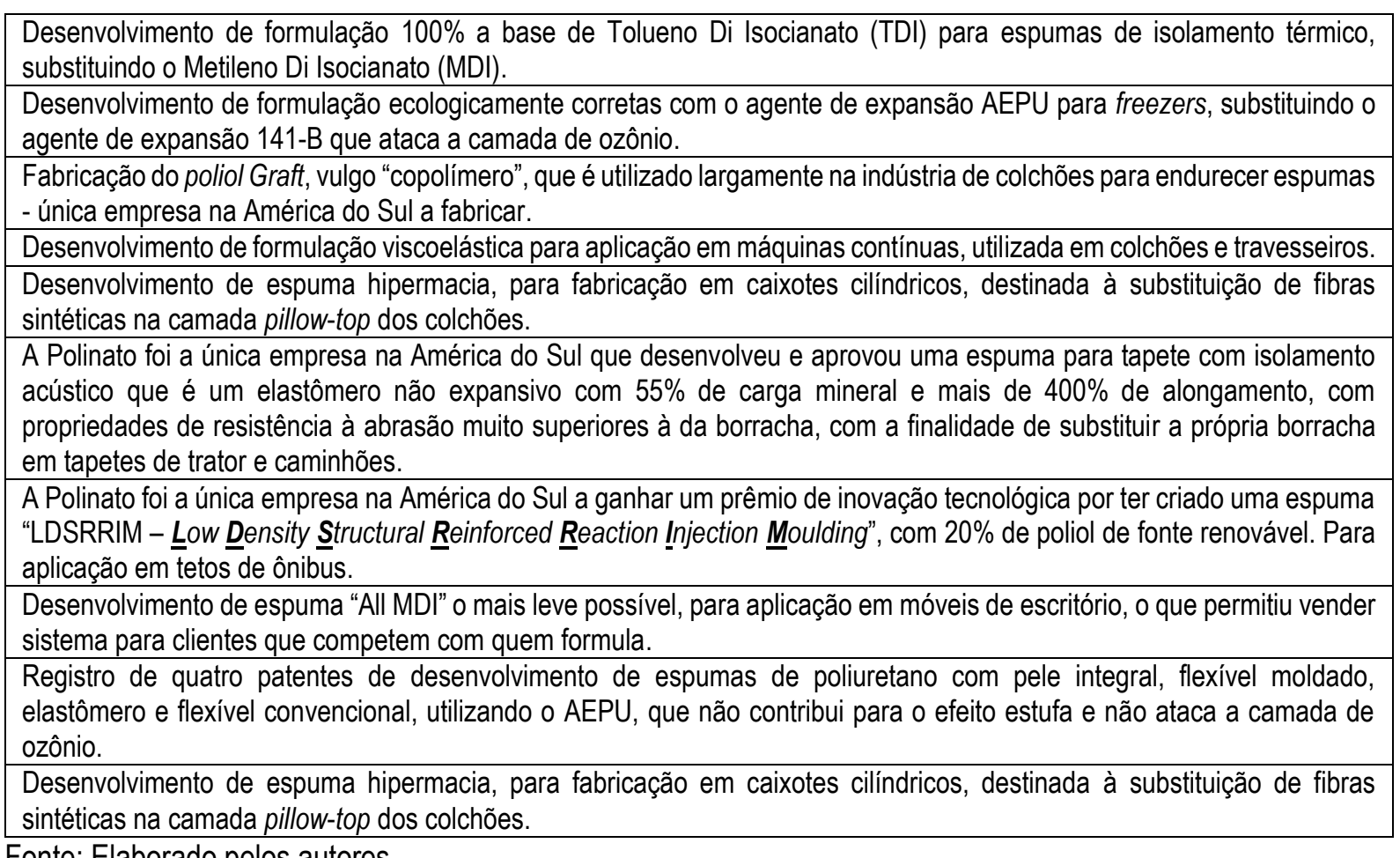

Fonte: Elaborado pelos autores.

\subsection{Mercado e estratégia}

A Polinato é uma empresa de sistemas de poliuretano independente. Como tal teve de conceber uma estratégia própria para conquistar seu espaço no mercado. Esta estratégia significa atuar com inteligência. Tal posicionamento pressupõe aspectos como:

a. capacidade tecnológica de desenvolvimento de soluções integradas aos clientes;

b. customização total no fornecimento de produtos e processos;

c. estabelecimento de sólidas parcerias que permitam aos clientes ganhos facilmente mensuráveis.

Basicamente, a estratégia de atuar com inteligência significa buscar vencer pela velocidade e pela precisão, mais do que pela força e tamanho. Todavia, para que se possa entender melhor o funcionamento do mercado em que a Polinato se insere, é importante comentar como é constituído o poliuretano. Diferente de outros polímeros de unidade monomérica repetitiva como o "Polietileno", "Poliestireno" e o "Polipropileno", como exemplos, cuja peça final é obtida por meio de uma conformação térmica, o Poliuretano é obtido por uma reação química de um Polialcool com um Isocianato, formando a ligação "Uretana", que dá nome ao polímero (poliuretano). Os compostos contendo hidroxilas podem variar quanto ao peso molecular, natureza química e funcionalidade. Os isocianatos podem ser aromáticos, alifáticos, cicloalifáticos ou policíclicos. Esta flexibilidade de escolha de reagentes permite obter uma infinita variedade de compostos com diferentes propriedades físicas e químicas de acordo com necessidades específicas de uma determinada aplicação, desde um poliuretano flexível como 0 colchão para dormir, como um poliuretano bem rígido que imite o concreto.

Para facilitar a compreensão em relação ao modo como a Polinato concebe seu segmento de mercado, cabe uma explicação genérica de como o mercado se organiza. Grandes empresas multinacionais lideram o mercado dos produtos químicos que compõem o poliuretano. Ocorre que a adição de aditivos e catalisadores entre outros confere à reação novos produtos para variadas aplicações de inúmeros mercados, como automobilístico, 
construção civil, refrigeração, etc. Neste ponto, operam as chamadas "casas independentes de sistemas de poliuretanos formulados", empresas com profundo conhecimento de mercado, de aspectos químicos de formulação e aplicação e que desenvolvem formulações sob medida específicas para cada cliente. As grandes companhias possuem esta verticalização, com suas próprias casas de sistemas. As casas de sistemas de poliuretano que não são ligadas às grandes multinacionais são denominadas independentes. Independentes porque não pertencem às grandes companhias produtoras de matérias-primas. São empresas que pesquisam novas formulações e novos processos fabris.

Neste segmento de mercado é que a Polinato opera. A diferença é que a Polinato compra matérias-primas dos grandes players e concorre na ponta com as suas respectivas casas de sistemas. Consegue ser competitiva devido a sua agilidade e tecnologia. A próxima etapa da cadeia produtiva é composta por empresas transformadoras que, utilizando as tecnologias desenvolvidas pelas casas de sistemas, fabricam peças e as fornecem para as indústrias manufatureiras.

Neste mercado, a Polinato é responsável pelo fornecimento de 9.000 toneladas/ano em média. É, portanto, líder no segmento de indústrias independentes de poliuretanos formulados sob medida. Na Tabela 4 é possível visualizar o cálculo da participação de mercado da Polinato por segmento:

Tabela 4 - Percentual de mercado da Polinato

\begin{tabular}{l|c|c}
\hline \multicolumn{1}{c|}{ Produtos } & Mercado total & Polinato \\
\hline $\begin{array}{l}\text { Produtos químicos relacionados com poliuretanos (incluindo tintas e } \\
\text { outros). }\end{array}$ & 315.000 t/ano. & $2,86 \% ;$ \\
\hline $\begin{array}{l}\text { Volume de produtos formulados em casas de sistemas para } \\
\text { transformadores. }\end{array}$ & 80.000 t/ano & $11,25 \%$ \\
\hline Casas de sistemas independentes de poliuretanos formulados. & 13.000 t/ano & $70 \%$ \\
\hline
\end{tabular}

Fonte: Departamento Comercial da Polinato com base em contato com fornecedores.

Em termos da análise do mercado, por meio do tipo de produto final, é interessante notar que, embora colchões e estofados representem a maior parcela, em termos de volumes, outros mercados estão experimentando uma maior taxa de crescimento. Especialmente a produção de espumas rígidas usadas para construção, com apresentado na Tabela 5.

Tabela 5 - Mercado mundial de PU (\%) em 2001 e 2010

\begin{tabular}{l|c|c}
\hline \multicolumn{1}{c|}{ Produto/Aplicação } & $\mathbf{2 0 0 1}$ & $\mathbf{2 0 1 0}$ \\
\hline Colchões e estofados & 32 & 26 \\
\hline Calçados & 6 & 6 \\
\hline Elastômeros e RIM & 6 & 7 \\
\hline Espumas moldadas & 15 & 17 \\
\hline Revestimentos, adesivos e selantes & 18 & 19 \\
\hline Construção & 17 & 24 \\
\hline Equipamentos (isolamento térmico) & 6 & 5 \\
\hline
\end{tabular}

Fonte: SINPROQUIM - SP.

Desde os anos 90, o mercado latino-americano cresceu de 240 mil toneladas, para um consumo atual estimado em 600 mil toneladas anuais, representando cerca de $6 \%$ do mercado mundial. Os dados do setor calcularam, em 2010, crescimento no segmento em quase todos os países da America Latina, como apresentado na Tabela 6. 
Tabela 6 - Mercado Latino-Americano de PU (ton)/Taxa de Crescimento (\%)

\begin{tabular}{|c|c|c|c|c|c|c|c|c|c|c|c|c|}
\hline \multirow[t]{2}{*}{ País } & \multicolumn{3}{|c|}{ Espumas flexíveis } & \multicolumn{3}{|c|}{ Espumas rígidas } & \multicolumn{3}{|c|}{ CASE } & \multicolumn{3}{|c|}{ Total PU } \\
\hline & 2008 & 2010 & $\begin{array}{c}\text { Tax } \\
a\end{array}$ & 2008 & 2010 & $\begin{array}{c}\text { Tax } \\
\mathrm{a} \\
\end{array}$ & 2008 & 2010 & $\begin{array}{c}\text { Tax } \\
a \\
\end{array}$ & 2008 & 2010 & $\begin{array}{c}\text { Tax } \\
a \\
\end{array}$ \\
\hline Argentina & 24.350 & 27.300 & 2,3 & 6.550 & 6.610 & 0,2 & 2.780 & 2,070 & $-5,7$ & 33.680 & 35.980 & 1,3 \\
\hline Brasil & $\begin{array}{c}187.60 \\
0\end{array}$ & $\begin{array}{c}242.10 \\
0\end{array}$ & 5,2 & 43.250 & 48.780 & 2,4 & 60.800 & $\begin{array}{c}76.00 \\
0\end{array}$ & 4,6 & $\begin{array}{c}291.65 \\
0\end{array}$ & $\begin{array}{c}366.88 \\
0\end{array}$ & 4,7 \\
\hline Chile & 18.700 & 20.720 & 2,0 & 3.800 & 4.350 & 2,7 & 1.700 & 2.110 & 4,4 & 24.230 & 27.180 & 2,3 \\
\hline Colômbia & 17.880 & 21.840 & 4,1 & 1.600 & 1.860 & 3,1 & 1.880 & 1.880 & 0,0 & 21.360 & 25.580 & 4,7 \\
\hline México & 84.500 & $\begin{array}{c}104.30 \\
0\end{array}$ & 4,3 & 38.950 & 47.900 & 4,2 & 32.490 & $\begin{array}{c}38.63 \\
0\end{array}$ & 3,5 & $\begin{array}{c}155.94 \\
0 \\
\end{array}$ & $\begin{array}{c}190.83 \\
0\end{array}$ & 4,1 \\
\hline Peru & 10.500 & 13.570 & 5,3 & 2.400 & 2.820 & 3,3 & 400 & 450 & 2,4 & 13.300 & 16.840 & 4,8 \\
\hline $\begin{array}{l}\text { Venezuel } \\
\mathrm{a}\end{array}$ & 14.580 & 15.500 & 1,2 & 1.230 & 1.400 & 2,6 & 6.250 & 5.900 & $-1,1$ & 22.060 & 22.800 & 0,7 \\
\hline Outros & 25.300 & 32.350 & 5,0 & 2.750 & 3.050 & 2,1 & 800 & 1.100 & 6,6 & 28.850 & 36.500 & 4,8 \\
\hline Total & $\begin{array}{c}383.44 \\
0\end{array}$ & $\begin{array}{c}477.68 \\
0\end{array}$ & 4,5 & $\begin{array}{c}100.53 \\
0 \\
\end{array}$ & $\begin{array}{c}116.77 \\
0 \\
\end{array}$ & 3,0 & $\begin{array}{c}107.10 \\
0 \\
\end{array}$ & $\begin{array}{c}36.50 \\
0\end{array}$ & 3,7 & $\begin{array}{c}591.07 \\
0 \\
\end{array}$ & $\begin{array}{c}722.59 \\
0\end{array}$ & 4,1 \\
\hline
\end{tabular}

Fonte: SINPROQUIM - SP.

Os dados de mercado do Brasil e da América Latina, em 2010, indicavam a tendência de substituição de outros materiais por poliuretanos. Observando a tendência e alinhando a busca de alternativas ecologicamente corretas, a Polinato percebeu-se capaz de crescer significativamente no mercado disponível para os produtos e as tecnologias que estavam em projeto de desenvolvimento. No entanto, para que isso se tornasse realidade, a empresa precisaria de investimento para concretizar esta estratégia de crescimento da organização. Foi quando um dos sócios buscou mais informações sobre os editais de fomento do Finep.

\section{O PROJETO DE INOVAÇÃO E UM NOVO PASSO PARA A POLINATO}

Desde a sua fundação e em toda a trajetória da Polinato, o desenvolvimento empresarial e do volume de conhecimentos complexos sempre foi financiado com recursos de curto prazo, com taxas muito elevadas para este fim. Estes financiamentos de recursos impactaram os resultados da empresa.

Em 2010, os gestores deram-se por conta que, para continuar desenvolvendo ações de inovação na Polinato para atender à crescente demanda do mercado, era necessário buscar novas fontes de fomento com menores taxas. Foi então que a empresa submeteu um projeto de inovação ao FINEP. Neste projeto de inovação a empresa propôs utilizar os gastos com recursos financiados em longo prazo, com taxas adequadas ao tipo de investimentos realizados. Pelo projeto, a empresa recebe do Finep o valor de $\mathrm{R} \$ 10.000 .000,00$ (dez milhões) para ser amortizado em 6 (seis) anos, com mais 2 (dois) anos de carência a uma taxa anual de $5 \%, 0$ que é muito abaixo das taxas de crédito disponíveis no mercado.

O objetivo do projeto foi o financiamento do Programa de Pesquisa, Desenvolvimento e Inovação da empresa durante 24 meses, denominado "Millenium". O projeto inclui a modernização do laboratório existente, a instalação de uma planta-piloto (que no seu conjunto formarão o Centro Tecnológico Polinato - CTP) e o desenvolvimento de produtos inovadores na sede da empresa na cidade de Sorocaba, Estado de São Paulo.

O Projeto contempla o desenvolvimento de produtos para diversas aplicações com a utilização de um revolucionário agente expansor, denominado AEPU, lembrando que a Polinato é a única empresa licenciada na América Latina para utilização desse agente, homologado pela $\mathrm{ONU}^{5}$ como alternativa ecologicamente correta para a fabricação de isolantes térmicos que demandem agente expansor. A questão do impacto ambiental é uma grande preocupação dos diversos segmentos industriais cujos poliuretanos são aplicados. Esta será outra importante atividade do projeto: desenvolver um poliol de fonte renovável, a partir da "quebra" de óleos vegetais. O Programa de P\&D+I da Polinato prevê a modernização da plataforma física dos laboratórios da empresa, bem como a capacitação das equipes ligadas a todas as atividades de inovação da companhia.

5 Organização das Nações Unidas. 
Esta capacitação não envolve apenas investimentos com treinamento, mas especialmente em equipamentos para o desenvolvimento de produtos e processos nas mesmas condições dos clientes e a realização de testes e ensaios. Os segmentos industriais mais representativos da aplicação dos poliuretanos são justamente as indústrias manufatureiras. Um centro tecnológico e uma planta piloto totalmente equipados e em condições de trabalhar de igual para igual com outros centros tecnológicos internacionais são fundamentais para participar de projetos que envolvam tecnologias de ponta na fronteira do conhecimento.

Em síntese, o Projeto Millenium prevê investimentos em três grandes eixos:

a. Modernização dos seus laboratórios, transformando-os num Centro Tecnológico;

b. O desenvolvimento de novas famílias de produtos inovadores, em especial com a utilização de agentes do AEPU;

c. Instalação de uma planta-piloto para aumentar a velocidade de resposta às demandas dos seus clientes, fornecendo soluções do tipo "taylor made" (sob medida), já com o processo definido e os testes realizados, garantindo a performance desejada de acordo com as mais diversas normas existentes.

Com a execução deste projeto, os sócios da Polinato acreditam que a empresa estará preparada e pronta para responder com eficiência às tendências de mercado identificadas pela equipe de projeto. Além dos avanços na parte tecnológica, outro fator muito importante justifica o presente investimento: a questão econômica. Assinar o edital de inovação seria disponibilizar uma quantidade de recursos jamais disponível nos processos da empresa. 0 investimento de $R \$ 10$ milhões era o mais alto na história da empresa. Isso corresponderia a um passo importante na área de inovação da empresa.

Os sócios Clodoaldo, Piero e Nóe não tinham dúvida que a empresa tinha potencial para inovar, mas será que eles estavam prontos para um projeto desta dimensão? No momento, aceitar o edital de inovação do Finep é a melhor estratégia para a empresa? Será que os sócios não deveriam levar o projeto de forma gradual, investindo menos recursos em maior prazo? E se o projeto desse errado, como ficaria a sustentabilidade da empresa? Eis então o dilema dos sócios da Polinato: assinar ou não o contrato de investimento do Finep? 


\section{NOTAS DE ENSINO}

\section{OBJETIVOS EDUCACIONAIS}

Edgar Morin (2001), em seu estudo encomendado pela Unesco, discute quais seriam "os saberes" essenciais para a convivência nos tempos atuais. Como resultado, Morin defende que a "a única certeza é que tudo vai mudar". Esta é reflexão do autor, ao apontar as incertezas da sociedade, do seu ambiente e dos saberes a serem desenvolvidos pelos indivíduos neste contexto. Por isso, este caso para ensino trata da inovação constante e da evolução histórica da Polinato em um ambiente marcado pela incerteza. Este estudo busca incentivar 0 aluno a analisar 0 cenário atual e prospectar cenários futuros, considerando as características de diferenciação da empresa em relação ao mercado, o empreendedorismo e as reflexões sobre inovação. 0 caso foi elaborado para utilização em disciplinas relacionadas à estratégia empresarial, à inovação, ao empreendedorismo, preferencialmente aos cursos de graduação e pós-graduação.

\section{FONTES DE DADOS}

As informações necessárias para a elaboração desse caso para ensino foram obtidas por meio de entrevistas concedidas pelos dirigentes da empresa. Também foi realizada busca em documentos e histórico da empresa, bem como as observações dos pesquisadores, o que configura a triangulação das informações obtidas para a elaboração do caso. A fim de preservar a identificação da empresa e dos sócios, os nomes dos mesmos foram alterados para este caso.

\section{APLICAÇÃO E ANÁLISE}

A proposta para a aplicação do caso inicia com o instrutor apresentando a introdução, com o propósito de instigar o aluno a conhecer a empresa e seu caso. 0 instrutor pode solicitar que os alunos realizem a leitura da caracterização da empresa de forma detalhada. Logo após, o instrutor pode dividir a turma em grupos, de no máximo 3 pessoas para que o cenário do dilema seja discutido no pequeno grupo, afim de observar as ideias iniciais a respeito do caso e compará-las com as dos demais membros do grupo, favorecendo o entendimento da situação. Após esta etapa, o instrutor pode apresentar aos grupos as questões para discussão (apresentadas na seção 3). No final, sugere-se uma discussão com todos os grupos em conjunto.

Segundo Yoshikuni (2008), o caso não é uma versão de sucesso ou fracasso. É uma descrição de uma situação específica a partir de diversos pontos de vista. O processo de chegar as suas próprias conclusões e tomar uma posição do que você faria em circunstâncias similares é o aspecto mais importante do método. Para preparar a análise de um caso, o autor sugere cinco passos, dispostos a seguir. Sugere-se que esses passos sejam passados para os alunos terem maior facilidade na atividade.

a. Identificar o tópico do caso e concentrar-se nesta área.

b. Ler o caso rapidamente perguntando: "Qual é genericamente o foco deste caso e que tipo de informações estão sendo fornecidas para análise?"

c. Ler o caso cuidadosamente. Agora, tentar colocar-se na posição do diretor responsável e perguntar: "Quais são os problemas-chave"?

d. Anotar os problemas no papel. Voltar ao caso e destacar considerações relevantes para cada área do problema.

e. Desenvolver as recomendações suportadas pela análise das informações do caso.

Cada grupo poderá ter rotatividade de líder, cuja função é manter a discussão ordenada, envolvendo todos os membros do grupo e contemplando todos os pontos de vista. Este líder não deve perseguir o consenso ou um único plano de ação ou resposta, mas identificar e analisar alternativas.

A discussão final do caso com todos os participantes e com a ajuda do professor vai explorar todos os pontos de vista e opiniões. Por isso, não é o objetivo do professor estabelecer o que é certo ou errado, e sim identificar as principais alternativas para discussão. 


\section{QUESTÕES PARA DISCUSSÃO}

Tendo em vista os objetivos educacionais propostos, pode-se realizar 4 questões a serem discutidas com os alunos, sendo elas:

a. Na história da empresa, percebe-se que a Polinato sempre considerou a inovação como parte fundamental da sua "competência essencial" ("core competence - do Levit), o que resultou em amplo conhecimento técnico sobre os produtos e os processos, além de grande capacidade para inovar. Por outro lado, o endividamento da empresa continua relativamente alto. 0 que o financiamento do projeto de inovação representa para o momento que a empresa vive?

b. Quais são os possíveis impactos negativos de aceitar o financiamento do projeto de inovação? Tais impactos negativos podem ser neutralizados pela capacidade de inovação da empresa?

c. Quais ações, no contexto do projeto descrito, a empresa pode implementar para aumentar a sua rentabilidade e a sua lucratividade?

d. Se você fosse um consultor desta empresa, qual seria o seu posicionamento em relação à opção mais viável para a empresa crescer de forma sustentável?

As questões buscam incitar os alunos a analisarem os dados antes de tomar suas decisões, contextualizando assim o cenário que a Polinato enfrentou neste momento. A contratação de financiamentos é frequente no mundo empresarial, sendo esta uma decisão importante. Este caso leva 0 aluno a se colocar na posição de tomador de decisão, o que o favorece a reflexão sobre diversos temas relacionados à administração de uma empresa de forma prática.

\section{ANÁLISE DO CASO}

A relação entre conhecimento e inovação se caracteriza pela combinação de diferentes conhecimentos e experiência, por meio de experimentos passados ou de processos de busca, como tecnologias, mercados e ações da concorrência. Para Tidd, Bessant e Pavitt (2008), a gestão da inovação supõe a mobilização de recursos para minimizar as incertezas por meio de sua transformação em conhecimento e aprendizado. Schumpeter (1988) já indicava que o conhecimento é um recurso econômico básico fundamentado na inovação por meio de um processo dinâmico de mudança tecnológica. Nesse sentido, investir em inovação significa para a Polinato combinar tecnologia e conhecimento com as demandas do mercado (TIDD; BESSANT; PAVITT, 2008). Um fabricante de colchões terá mais facilidade para vender seus produtos se estes apresentarem diferenciais competitivos, tais como melhor qualidade percebida, maciez, conforto, resistência a micro-organismos, redução no custo de produção, etc. Todos estes diferenciais dependem de formulações químicas ou de mudanças no processo industrial. Estas demandas são apresentadas para empresas como a Polinato. Ela precisa de recursos para custear os estudos, os ensaios em laboratório, as formulações de bancada, os protótipos e as amostras. Caso este esforço por inovar resulte numa formulação viável, esta será comprada pelos clientes, gerando valor econômico para a empresa (SHUMPETER, 1988). Porém, até este momento é necessário assegurar recursos financeiros para custear todas as etapas do desenvolvimento, até sua entrega (remuneração do pessoal, das consultorias técnicas, dos insumos, energia, viagens, etc.). Da mesma forma, um fabricante de geladeiras, freezers ou câmaras frigoríficas demandará por novas formulações com agentes expansores e propriedades físicoquímicas diferenciadas, mais eficientes e de menor custo. $O$ desenvolvimento deste tipo de produto requer gastos iniciais e envolve risco tecnológico, pois se trata de conceber algo novo, inexistente.

Além disso, a inovação requer um esforço sistemático de gestão, alto grau de organização, diversidade, autonomia de equipes e criatividade. Christensen (2003) afirma que, mesmo escutando atentamente seus mercados e investindo agressivamente em tecnologias, algumas empresas perdem domínio de mercado. Isso se deve, segundo o autor, às falhas na gestão estratégica da inovação. Nesse aspecto, a experiência da Polinato no campo da inovação pode neutralizar alguns riscos. O timming é muito importante no tipo de inovação da Polinato, destinada às indústrias de transformação ou manufatureiras. É preciso alcançar os objetivos dos produtos inovadores no tempo certo. Antecipar-se a uma demanda pode ser tão prejudicial quanto atrasar uma entrega aos clientes. $O$ rápido, e sustentável, crescimento da Polinato se deu em parte exatamente por possuir uma gestão da inovação bem executada. As equipes são coordenadas pessoalmente por um dos Diretores e são multidisciplinares. A Direção e a alta gerência da empresa participam constantemente de fóruns, congressos, seminários, feiras e demais eventos dos seus setores de atuação. $O$ volume de dados e informações coletados

Revista Alcance - Eletrônica - vol. 25 - n. 1 - Jan./Abr. 2018 
permite à empresa reduzir o risco de inovar fora do tempo certo, ou em rota tecnológica inviável (CHRISTENSEN, 2003). Este fato pode ser comprovado pelo crescimento da empresa, pelo perfil dos clientes, em sua maioria líderes nacionais em seus segmentos de mercado e pelas formulações desenvolvidas, em sua maioria exclusivas por serem difíceis de copiar. Por outro lado, os aspectos financeiros envolvidos na gestão da inovação não podem ser negligenciados. Os números da empresa indicam que até o momento os gastos com inovação estão sendo suportados por recursos de terceiros e de curto prazo. Este fato tem impacto na necessidade de capital de giro da empresa, como pode ser observado na participação relevante do Passivo Circulante e no reduzido valor do Patrimônio Líquido (Tabela 2).

De acordo com Christensen (2001), em processos inovadores disruptivos, muitas vezes é mais estratégico investir em pequenos mercados que proporcionam maiores margens de resultado do que em mercados substanciais que pedem produtos de baixa performance e que proporcionam pequenas margens de resultado. Estes aspectos dizem respeito à gestão estratégica da inovação (CHRISTENSEN, 2001). Para a Polinato, a inovação gerada pela infraestrutura de P\&D possibilitará a entrada da empresa em outras cadeias produtivas, de alto valor agregado e com margens maiores de resultados. 0 resultado líquido da empresa apresenta trajetória ascendente nos últimos anos, o que confirma que a estratégia está correta, se considerado este objetivo. Possuir uma boa infraestrutura de pesquisa e desenvolvimento tem se mostrado um fator importante para vender produtos de maior valor agregado. A Polinato já atende diversas empresas líderes de mercado e que atuam em nichos, 0 que favorece aplicar melhores margens aos produtos. Os exemplos mais clássicos são as empresas que demandam por isolamento térmico e as indústrias automotivas que demandam por peças técnicas, de alto desempenho. As formulações que a Polinato desenvolve para estas aplicações não representa volumes gigantescos, como seriam formulações para fabricação de móveis e colchões, porém são formulações sofisticadas e de alto valor agregado.

\section{NOTAS COMPLEMENTARES PARA AUXÍLIO - A DECISÃO DA POLINATO}

A Polinato assinou o contrato de financiamento. Os recursos foram aplicados conforme o previsto, com destaque para a implantação do seu Centro de Tecnologia. Novas formulações de poliuretanos foram desenvolvidas no âmbito do projeto. $O$ destaque foi a família de produtos com o agente expansor AEPU. Novos clientes foram conquistados num formato de negócio inovador, no qual a Polinato, como fornecedor, e o cliente, como transformador, atuam numa parceria do tipo ganha-ganha, com foco nas necessidades dos clientes finais. A infraestrutura de P\&D, agora com um Centro de Tecnologia, propiciou que a empresa atendesse à cadeia de petróleo e gás. Ao mesmo tempo em que o projeto de inovação avançava, a alta direção realizou importantes ações relacionadas à governança da empresa, com a criação de um sistema de gestão integrada e a contratação de profissionais especializados para se ocuparem da administração da empresa nas suas diversas áreas: produção, finanças, comercial e gestão de pessoas. Com estas ações, a qualidade das vendas, do financiamento das operações e a produtividade melhoraram com reflexos positivos na rentabilidade da empresa. 


\section{REFERÊNCIAS}

BESSANT, J.; TIDD, J. Inovação e empreendedorismo: administração. Bookman, 2009.

BONTEMPO, P. C.; COIMBRA, F. C.; POLO, E. F. Os limites do crescimento pela inovação: 0 caso da empresa gama cosméticos. RAl: revista de administração e inovação, v. 5, n. 3, p. 42-54, 2009.

CHRISTENSEN, C. M. 0 dilema da inovação. São Paulo: Makron Books, 2001.

CHRISTENSEN, C. M.; RAYNOR, M. E. 0 crescimento pela inovação: como crescer de forma sustentada e reinventar o sucesso. Elsevier, 2003.

MORIN, E. Os sete Saberes Necessários à Educação do Futuro. 3. ed. São Paulo, Cortez; Brasília, DF: UNESCO, 2001.

PWC - PricewaterhouseCoopers. Innovation Imperative: Keeping your company relevant. 2012. Disponível em: $\quad$ https://www.pwc.com/en_GX/gx/consulting-services/innovation/assets/pwc-gyb-innovation-imperativekeeping-your-company-relevant.pdf

SCHUMPETER, J. A. The theory of economic development: An inquiry into profits, capital, credit, interest, and the business cycle. Transaction publishers, 1934.

SINPROQUIM - SP. Indicies Econômicos. Disponivel em: http://www.sinproquim.org.br/indices.

YOSHIKUNI, A. C. Apostila de Pós-Graduação em Estratégia Empresarial. Material de apoio e estudo Fundação Getúlio Vargas, São Paulo, jun. 2008.

\section{BIBLIOGRAFIA RECOMENDADA 6}

BROWN, J. R.; FAZZARI, S. M.; PETERSEN, B. C. Financing innovation and growth: Cash flow, external equity, and the 1990s R\&D boom. The Journal of Finance, v. 64, n. 1, p. 151-185, 2009.

CHO, H.-J.; PUCIK, V. Relationship between innovativeness, quality, growth, profitability, and market value. Strategic management journal, v. 26, n. 6, p. 555-575, 2005.

COAD, A.; SEGARRA, A.; TERUEL, M. Innovation and firm growth: Does firm age play a role?. Research Policy, v. 45, n. 2 , p. 387-400, 2016.

FOELLMI, R.; ZWEIMÜLLER, J. Is Inequality Harmful for Innovation and Growth?: Price versus Market Size Effects. Journal of Evolutionary Economics, v. 26 n. 1, 2016.

HERRERA, M. E. B. Innovation for impact: Business innovation for inclusive growth. Journal of Business Research, v. 69, n. 5, 2016.

JOHNSON, M. W.; CHRISTENSEN, C. M.; KAGERMANN, H. Reinventing your business model. Harvard business review, v. 86, n. 12, p. 57-68, 2008.

\footnotetext{
${ }_{6}^{6}$ Para a bibliografia recomenda elencaram-se obras internacionais, sendo trabalhos considerados seminais e trabalhos recentes que contemplem as discussões recentes de literatura sobre a temática. A bibliografia recomendada oferece uma base teórica para o desenvolvimento de novos estudos que relacionem a inovação e o crescimento da organização.
}

Revista Alcance - Eletrônica - vol. 25 - n. 1 - Jan./Abr. 2018 